\title{
Global Problems of Development of the Agglomeration Transport Systems
}

\author{
Norair Bludyan ${ }^{1 *}$ \\ ${ }^{1}$ Moscow Automobile and Road Construction State Technical University (MADI), 64 Leningradsky \\ prosp., 125319, Moscow, Russia
}

\begin{abstract}
The article describes the trends of development of the agglomeration transport systems and scientific and methodological problems of territorial-transport forecasting and planning. Native and international experience in the use of "large amounts of data" in the organization of passenger transport was considered. Promising areas of agglomeration transport systems were determined.
\end{abstract}

\section{Introduction}

In recent years, a broad discussion of global trends and approaches to the development of large agglomeration formations and their transport systems began in a scientific and practical environment. Trends in the development of transport systems of the world's largest agglomerations were the subject of the fifth meeting of the International Expert Council on transport issues at the government of Moscow and the Moscow Urban Forum 2017 The event was attended by recognized international experts, researchers and practitioners from all of the leading countries in this field: the United States, China, England, Germany, Holland, Israel, Spain, France, Belgium, Sweden, Japan, Korea and others. The analysis of materials of more than 100 reports, the systematization of the results of these forums over the past three to four years and the comparison of trends in the development of transport systems make it possible to draw the following global conclusions:

1. The world has entered the era of agglomeration development, and transport is its most important integral component. Moscow is in the forefront of these development trends.

2. The transport system in the largest agglomerations is an integrated megaproject, which largely determines the growth and development of the agglomerations themselves.

3. Hyper-connectivity of various models of transport in transport systems. New models of multimodal urban mobility and transport planning [1-6].

\section{Research of agglomeration of Moscow}

Determination of parameters and characteristics of large territorial entities and names in the context of the problem hitherto is relatively conventional. The terms "region", "megalopolis",

* Corresponding author: $\underline{\text { np-tama@mail.ru }}$ 
"agglomeration", etc. in the interpretation of different specialists have different essence and content.

As a rule, megalopolis is a big city, which formed by the merger of separate settlements and smaller cities. According to experts megalopolis should be considered as city with a multi million population. The generally accepted gradation of megalopolis and agglomerations does not currently exist, but it is conditionally considered that agglomeration is a larger territorial formation. In the world practice, agglomerations are understood as large cities with suburbs with a population of 15-25 million people.

The conducted researches allowed scientists to reveal specific features of agglomerations [7]. As a rule, there is a main central city surrounded by smaller ones, but they have common transport, energy, water and other communications.

According to the draft federal law [8] a megapolis - is the "administrative - territorial unit with a special status. It is proposed to establish that the population of a megalopolis must be at least one million people". It is important to note that the metropolis should have a single administrative authority.

It is known that this bill is withdrawn, because it contradicted the current legislation in many respects. In our opinion, such a classification of territories is unacceptable for the purposes of transport planning of passenger systems. The scatter of the number of the population from one million to 10 or 15 million people in a priori assume completely different approaches to the problems of transport planning.

Research of the UN processes on urbanization have shown a steady global trend in urban population growth. According to UN standards, cities with a population of more than 10 million people can be referred to "megapolis" [7].

According to some experts [9], territorial and transport planning as a type of activity is part of urban planning and territorial planning. Now the main practical disadvantage is the lack of synchronization of transport planning problems with other activities. These shortcomings lead in practice to the inability to reserve land plots for transport infrastructure, especially in urban conditions, to increase the priority of public transport.

The effective functioning of transport systems in agglomerations is possible only if the balance of interests is observed. Thus, the most important component of the territorial planning in the urban planning is the organization of the transport system. Some aspects of the alternative approach to the concept of the development of the transport system In the Moscow agglomeration were considered in [10].

At the meeting held on 21 November 2016 of the Presidium of the Presidential Council of the Russian Federation on Strategic Development and the priority projects passport priority project "Safety and quality of the road" was approved [11]. Transport infrastructure integrated development's program in largest urban agglomerations (TIIDP) is identified as one of the main means for achieving the objectives.

The term "agglomeration" is interpreted as the formed by the largest urban district - the "core agglomeration" and municipalities - "sputniks", multicomponent system with intense industrial, transport and cultural ties, in particular, pendulum migration of the population per one day. The term "urban agglomeration road network" means the totality located on the territory of the urban agglomeration public roads of local, regional and federal levels, as well as the following objects of the road network:

- highways of high-speed and adjustable traffic;

- main streets of continuous and controlled city traffic, transport and pedestrian district value;

- streets and roads of local value (most loaded), the streets in residential areas, streets and roads in the research and production, industrial and municipal storage zones (areas).

TIIDP is developed and implemented by the administrations of the Russian Federation jointly with the federal executive authorities, municipal administrations and owners of the 
roads. PKRTI should include consolidation of resources from all possible sources (federal programs, regional and municipal programs, etc.) to identify identified priority tasks.

The implementation of the TIIDP should ensure the solution of the following priority tasks:

1. Ensuring the necessary level of road safety on the road network of urban agglomerations, including in terms of reducing the concentration of road accidents on the road network (including by using cable and barrier fencing, lighting, and artificial uneven nesses in the road network for speed limits, equipment of intersections and ground pedestrian crossings by means of lighting and traffic signal regulation, equipping ground pedestrian crossings and public transport stops with protective and information equipment, introduction of speed limits and other measures);

2.Bringing the road network of urban agglomerations into the normative transportoperational state (by carrying out the corresponding road works);

3.Elimination of the congestion of the urban agglomerations road network, including by switching cargo transportation to other modes of transport, transporting passengers to public transport, optimizing traffic flows, improving the efficiency of the traffic management system, moving to modern models of transport infrastructure development using complex schemes organization of transport services for the public by public transport, synchronization of the development of all modes of transport and transport infrastructure hands;

4.Increasing of the level of citizens' satisfaction of the urban agglomeration's road network.

Moscow agglomeration is the largest territory of the Russian Federation. In this regard, the planning system of the passenger within the existing separate administrative regulation in Moscow and the Moscow Region is a serious problem. The most important specificity of this problem is the impossibility of mechanical restriction of this sphere within the framework of an individual subject.

The key task of the territorial-transport planning in the Moscow agglomeration is to determine its conditional border. Our analysis of previously performed studies has shown that the most substantiated variant was proposed in [12]. As a result of the conducted studies, the authors proposed a version of the Moscow agglomeration zone in the form of four belts.

Post-industrial changes in the economy of the Moscow region strengthen the role of service functions as city-forming and in the so-called "marginal" or "terminal" cities of agglomeration. This increases the number and variety of jobs and the distribution of labor resources. There is a change in the regularities and characteristics of the passengers' pendular transport.

The city of Moscow is the core of the Moscow agglomeration and the most important link both in the country and in the very agglomeration. Over the past 25 years of market reforms, Moscow has completely modernized and redeveloped its economy and began to develop as a global cultural, financial, sporting and economically stable center.

The functional unity of the Moscow agglomeration is due to the territorial integrity of the city and the region, the existence of sustainable transport links between them. The common transport and communication infrastructure, the pendular passenger traffic, sustainable economic, financial, cultural and recreational connections make it possible to consider this system as a whole.

\section{The main provisions of the development strategy of the Moscow agglomeration transport system}

The strategy for the development of the passenger transportation system in the Moscow metropolitan area should be based on the following four key priorities, and the goal should be creating transport "personally for each passenger". 
The personalized approach to the passenger includes:

- correct and timely information,

- convenient feedback mechanism.

Application of new technologies:

- mobile applications and convenient payment methods,

- new ways of movement.

Optimization of transport network:

- continuous development of the route network,

- management of traffic flows.

Security on all modes of transport:

- safety of passenger traffic,

- reduction in accidents on personal transport,

- interaction with law enforcement agencies.

The modern agglomeration generates huge amounts of information that must be used to solve the problems of achieving strategic priorities for the development of the transport system.

Table 1 shows the data of the Department of Transport and Development of Road and Transport Infrastructure in Moscow in terms of the amount of information is currently generated [13].

Table 1. Number of records per year

\begin{tabular}{|c|c|c|c|c|c|}
\hline $\begin{array}{c}\text { Cameras } \\
\text { photo-video } \\
\text { recording 1 }\end{array}$ & $\begin{array}{c}\text { Tracks } \\
\text { public } \\
\text { transport }\end{array}$ & $\begin{array}{c}\text { parking } \\
\text { session }\end{array}$ & $\begin{array}{c}\text { Data on the } \\
\text { passage in } \\
\text { the subway } \\
\text { and NGPT }\end{array}$ & $\begin{array}{c}\text { Sessions of } \\
\text { public Wi-Fi }\end{array}$ & $\begin{array}{c}\text { Mobile app } \\
\text { data }\end{array}$ \\
\hline$>7000000000$ & $>10$ billion & $>100$ million & $>7000000000$ & $>3000000000$ & $>3000000000$ \\
\hline
\end{tabular}

The annual volume of data is comparable to the volume of all books in the Russian State Library.

Intelligent transport system processes as much information per day as Sberbank of Russia (including data from mobile complexes).

In the agglomerations of foreign countries, a great deal of experience has been accumulated in the generation and use of large volumes of information in solving transport problems.

Table 2 shows the analysis of the use of large data sets (Big Data) in the city of Moscow and other urban agglomerations abroad [14].

Studies using "large data sets" are also conducted by some companies of search engines ("Yandex", Uber).

The company "Yandex" carried out an assessment of the correspondence of passengers in the message "House - work; work home" [15]. The daily cycle of correspondence was received using "Yandex Navigator" and "Yandex Map". According to the analysis, Moscow districts were divided into residential, workers and mixed, as well as analyzed the time characteristics: departure and arrival; movement, an assessment of the impact of the MAC load was also carried out.

The studies of the use of smartphones by the citizens of the National Taras Shevchenko University made it possible to obtain information on passenger traffic at the stopping points. The research method is to estimate the number of people using the Yandex. Transport application in the immediate vicinity of the stopping point [16].

Uber, using its Movement service, determines the correspondence matrix by time [17]. 
Table 2. Use of "large data" in the largest cities (according to the PWC)

\begin{tabular}{|c|c|c|c|c|c|}
\hline technology I City & Moscow & Barcelona & London & New York & Sydney \\
\hline $\begin{array}{c}\text { Situation Traffic Control } \\
\text { Center }\end{array}$ & + & + & + & + & + \\
\hline $\begin{array}{c}\text { automatic control of traffic } \\
\text { signals System }\end{array}$ & + & + & + & + & + \\
\hline $\begin{array}{c}\text { Driver Information System of } \\
\text { filling the parking spaces }\end{array}$ & + & + & + & + & $\mathrm{n} / \mathrm{d}$ \\
\hline $\begin{array}{c}\text { automatic call system of } \\
\text { emergency services in the } \\
\text { event of accidents (e-call) }\end{array}$ & - & $\mathrm{n} / \mathrm{d}$ & $\mathrm{n} / \mathrm{d}$ & $\mathrm{n} / \mathrm{d}$ & $\mathrm{n} / \mathrm{d}$ \\
\hline $\begin{array}{c}\text { Driver Alert Control } \\
\text { (accident, congestion UDS) }\end{array}$ & + & $\mathrm{n} / \mathrm{d}$ & + & + & + \\
\hline $\begin{array}{c}\text { Obtaining information on } \\
\text { passenger flows with a view } \\
\text { to improving route network } \\
\text { according to mobile } \\
\text { operators }\end{array}$ & + & + & + & + & + \\
\hline $\begin{array}{c}\text { rolling stock equipment } \\
\text { NGPT GLONASS or GPS }\end{array}$ & + & + & + & + & + \\
\hline $\begin{array}{c}\text { Using the priority system } \\
\text { traffic transport public by } \\
\text { regulating the traffic lights }\end{array}$ & $\mathbf{n} / \mathbf{d}$ & + & $\mathbf{n} / \mathbf{d}$ & + & $\mathbf{n} / \mathbf{d}$ \\
\hline Street lighting control system & $\mathbf{-}$ & $\mathbf{+}$ & $\mathbf{+}$ & $\mathbf{n} / \mathbf{d}$ & $\mathbf{+}$ \\
\hline $\begin{array}{c}\text { automatic roadway covering } \\
\text { control system }\end{array}$ & $\mathbf{n} / \mathbf{d}$ & $\mathbf{n} / \mathbf{d}$ & $\mathbf{n} / \mathbf{d}$ & $\mathbf{n} / \mathbf{d}$ & $\mathbf{n} / \mathbf{d}$ \\
\hline $\begin{array}{c}\text { Video surveillance cameras } \\
\text { on the roads }\end{array}$ & $\mathbf{+}$ & + & $\mathbf{+}$ & $\mathbf{+}$ & + \\
\hline
\end{tabular}

\section{Transport hubs in the agglomerations}

The most important role of transport interchange nodes (TIN) play in the formation and planning of agglomeration transport systems. TIN is an infrastructure facility transport system that provides multimodal transport arrangements in agglomeration. In general, the description of the multimodal transport through TIN is shown in Figure 1.

Megaproject Moscow agglomeration is introduced into operation in October 2016 Moscow Central Ring (MCR). MCR incorporates different network formed by its configuration TIN.

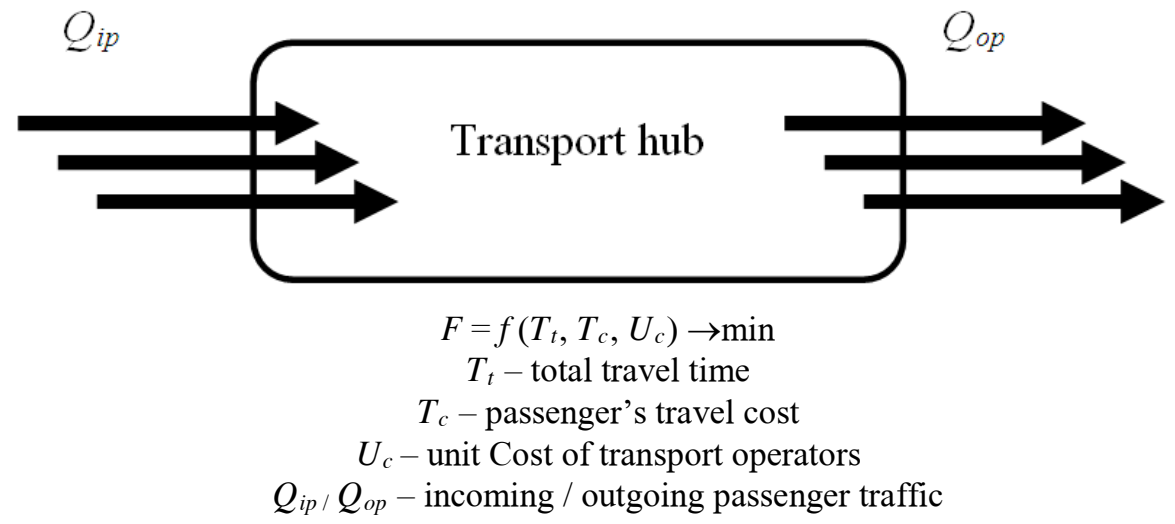

Fig. 1. Diagram of the organization of multimodal transport in the TIN. 
The length of the Moscow Central Ring is $54 \mathrm{~km}$., And the time for making a trip by one circle is 90 minutes. The MCR includes 31 TINs with transfers to land city passenger transport, 14 TINs with transfers to metro (17 in the long term), 6 TINs have transfers to suburban electric trains (10 in perspective). Four TINs have car parks (17 in perspective), open integration for 10 TINs with a subway and closed integration for 5 TINs with a subway. MCR includes 150 thousand square meters of technological areas and 1.1 million $\mathrm{m} 2$ of commercial space [18].

MCR is fully integrated into the network OPT(overland public transport): change tracking was conducted 13 operating routes, open 6 new routes, on 9 routes altered rolling release schedule, the transfer of 24 stopping points. Implemented branding stops 300 and 300 on the bus 28 routes OPT, 237 OPT routes have stop within $500 \mathrm{~m}$ from the MSC.

Responsibility for the operation of the MCR is divided between Metro and JSC "Russian Railways".

Transport service to the MCR includes the operation of rolling stock, passenger transport services for MCR and organization of advertising, trade and other commercial activities related to the use of the railway rolling stock.

Operation TH of MCR involves the collection of funds received as payment for tickets, control of travel and suppression of cases of ticketless travel, maintenance of passenger arrangement in good condition and safety to the MCR.

At MCR introduced modern innovative passenger services of the Moscow Metro. Navigation services include 5: Information stands, relevant and reliable information on the underground operation, tariff menus, help the work of the transport complex.

At MCR stations installed over 7000 essential elements of the passenger infrastructure and innovative services.

Before starting the MCR at the city portal "Active Citizen" passengers to choose than TH and further equip the station.

\section{Conclusion}

Further development of agglomeration transport systems will be based on the widespread information and communication technologies' introduction which will ensure efficient multimodal transport. In this regard, payment service is the main service:

- Development of passenger sintering systems - development of payment services for travel.

- A quantum leap in technology to handle large volumes of information (BigData) - the basis for a new approach to understanding the needs of the residents in the metropolitan area transportation.

- The introduction of the scheme "Financial statement ++ operator Transport operator " The way to improve people's lives.

- The smartphone will become the center of financial transactions and travel navigator.

- Functionality of tomorrow agglomeration - concentration of all financial transactions in a single device. Information about charges, contactless cards and payment of QR-codes, travel expenses, combined with the search for the optimal route.

The future of passenger transport is the agglomeration transport on demand. This implies:

Joint projects of financial operators and transport operators who use modern services, mobile technology and data transport operator will lead to a new model of using different modes of transport as a single vehicle.

IT platform, which includes a mobile application as an interface with the passenger, payment services for financial transactions, data traffic and transport congestion as a basis for analysis and route planning, select the most convenient route, reserve a place, if necessary, carry out the payment and create a chain reminders. 
Promising directions of using "big data" in solving transport problems in Moscow are:

- Reglament information interaction dispatching services order of taxicabs with joint regional navigation and information system.

- Using the data obtained, and mobile operators to develop data OPT night route network.

- Use of data for operational monitoring of compliance with the regime of work and rest of drivers.

- Correcting route network of the new model OPT and transport service parameters of the population.

\section{References}

1. N.O. Bludjan, R.S. Ajriev, M.A. Kudrjashov, Methodical bases of management of multimodal passenger transportations. In the world of scientific discoveries, 10 (70), pp 1249-1259 (2015)

2. N.O. Bludjan, R.S. Ajriev, F.V. Akopov, S. Real, Modern model for the organization of multimodal interregional passenger transport in the context of agglomeration. In the world of scientific discoveries, 6 (66), pp 233-242 (2015)

3. N.O. Bludjan, R.S. Ajriev, Agglomeration approaches to solving transport problems, Autotransport enterprise, 8, pp 2-7 (2014)

4. N.O. Bludjan, R.S. Ajriev, Agglomeration planning and organization of intersubject bus transportation in the Moscow region. Automation and control in technical systems, 3 (11), 2014, pp 34-47

5. N.O. Bludjan, R.S. Ajriev, F.V. Akopov, P.I. Hejfic, Demand management and integrated management of agglomeration passenger traffic. Automation and control in technical systems, 3 (11), pp 66-82 (2014)

6. M.V. Bojkova, I.N. Il'ina, M.G. The future of cities: cities as agents of globalization and innovation. Forsajt, 4, pp 32-48 (2011)

7. A.A. Semenov, Megapolis as a sociocultural phenomenon: to the problem of definition of the concept. //Youth scientific portal; (2013)

8. Draft Federal Law of Russian federation "On Megalopolises" of 09.12.2013 \# 4036756 (2013)

9. M.L. Petrovich, Territorial and transport planning is a new element of strategic planning // The official site of CJSC Petersburg NIPIgrad, 2009. September (2009)

10. N.O. Bludyan, Alternative approach to the concept of modernization of the transport system of the Moscow metropolis // Autotransport enterprise -2013.-№7. -FROM. 26.2013

11. Passport priority project "Safe and high-quality roads". Date Views 10.08 .2017 www.mintrans.ru/upload/iblock/e39/Паспорт\%20БКД.pdf

12. A.G. Mahrova, T.G. Nefedova, A.I. Treyvish, Moscow: the metropolis? agglomeration? Megalopolis? // Demoscope Weekly.2012. Aug. (2012)

13. Moscow transport in the "Smart City" - current status and development plans. Date Views 10.08.2017

http://transport.mos.ru/common/upload/docs/1499773692_20170704_smart_city_finalr u.pdf

14. The future is close: Urban Preparedness Index. Date Views 10.08.2017 http://www.pwc.ru/ru/assets/the-future-is-coming-russian.pdf 
15. Yandex research: Home - work, work - home. Date Views 10.08.2017. https://yandex.ru/company/researches/2016/home_work

16. Bus' stops in Moscow on weekdays and weekends. Date Views 10.08.2017 https://yandex.ru/company/researches/2017/public_transport_stops

17. Uber Movement. Date Views. 10.08.2017 https://movement.uber.com/cities?lang=enUS

18. Moscow Central Circle. Date Views. 10.08.2017. http://mosmetro.ru/mcc/ 